\title{
DOS VISIONES DEL ESPACIO MARINO COMO MODERNIDAD. ENTRE LA POESÍA DE RUBÉN DARÍO Y LA PINTURA DE JOAQUÍN SOROLLA
}

\author{
AlBERTO ACEREDA \\ Arizona State University
}

\begin{abstract}
El fin de siglo supuso en el mundo hispánico la aparición de unos artistas cuya actitud vital y estética definió una época fundamental para el pensamiento, el arte y la cultura y cuya expresión coincidió con el fenómeno multipolar que se ha llamado Modernismo. Sus realizaciones artísticas y, especialmente poéticas, marcaron el inicio hacia lo que aquí definiremos como modernidad. Uno de los espacios propios de esa modernidad fue el mar como paisaje aglutinador de la vida diaria y como búsqueda de los espacios libres que acompañaron la instauración de las sociedades industriales y el crecimiento de una pujante burguesía. La representación que de ese paisaje marino ofrecieron los pintores del fin de siglo y los poetas del Modernismo permite establecer algunas consideraciones que, a su vez, abren el camino a nuevas lecturas en torno a una encrucijada histórica clave para la cultura hispánica. En el marco modernista destaca la figura de Rubén Darío como una de las piezas fundamentales para el desarrollo de la posterior literatura er lengua española. Su obra, diversa, variante y hasta contradictoria, ha sido objeto de estudio y escrutinio en lo que hoy constituye uno de los más extensos aparatos críticos y bibliográficos dedicados a un autor concreto. La perpetuación de ciertas coordenadas críticas han derivado, sin embargo, en exégesis que con frecuencia no analizan de forma completa la obra dariana bajo el prisma de la modernidad, con sus consiguientes variantes y contradicciones ${ }^{1}$. Nuestro estudio se enmarca en la
\end{abstract}

\footnotetext{
${ }^{1}$ Las vías de aproximación crítica al Modernismo fueron ya señaladas por José $O$. Jiménez (1998: 41-7) mientras que los acercamientos fueron recopilados por Keith Ellis y Hensley C. Woodbridge.
}

Rlit, LXV, 129 (2003), 119-143 
reciente vía crítica revisionista del Modernismo y en la relectura de su vertiente poética dariana como testimonio de y para la modernidad ${ }^{2}$.

Para plantear la hipótesis de nuestra investigación partimos de dos premisas que podemos aceptar como provisionales puntos de partida. En primer lugar, juzgamos que en el desarrollo de la poesía hispánica desde fines del siglo XIX existen dos amplias fases generales sucesivas que, a grandes rasgos, son la fase modernista (desde 1880 hasta aproximadamente 1920) y la fase contemporánea (desde el inicio de las vanguardias en torno a 1920 hasta nuestros días). En segundo lugar, aceptamos que la fase modernista compone el primer acorde de la modernidad literaria contemporánea en lengua española, según ya demostró Octavio Paz. Desde ambas premisas, consideramos que Darío y los modernistas concibieron su obra literaria como poética ubicada ya en los estadios de la modernidad. Más particularmente, sostenemos como hipótesis que un sector de la representación pictórica finisecular, especialmente la pintura de Joaquín Sorolla, se alínea con la idea burguesa de percibir el espacio marino, y en él la playa, como locus amoenus y marco de diversión (modernidad de raíz socioeconómica); los poetas modernistas, y en concreto la poética de Darío, emplean el paisaje marino como espacio para la reflexión y meditación metafísica de carácter existencial (modernidad de raíz artística). La pintura de Sorolla entra así en una economía de mercado que afirma a la burguesía y supedita la estética a los gustos de sus compradores, que no son otros que los mismos burgueses. La poesía modernista de Darío, en cambio, niega la validez del paisaje marino como espacio exclusivo de diversión y aspira a un arte opuesto al materialismo y al utilitarismo burgués, lo que desemboca en la visión del mar como reflexión metafísica de signo existencial. La modernidad de la poética dariana radica, por tanto, en la utilización de un paisaje común, el mar, como espacio para la meditación por vía del arte sobre la problemática universalmente compartida de la existencia humana. La modernidad pictórica de Sorolla se basa en la representación artística de un espacio marino apartado de cualquier problemática, paisaje luminoso con fines socioeconómicos sustentado por un público burgués. Darío conoció la pintura de Sorolla y hasta en algún caso realizó breves comentarios de ella, lo que nos permitirá comprobar de manera más clara las diferencias en sus posicionamientos frente al arte y la modernidad. Para demostrar nuestra hipótesis, estructuramos nuestro estudio en tres apartados seguidos de unas conclusiones finales. El primer apartado desarrolla las conexiones teóricas y artísticas entre el fin de siglo modernista y la modernidad. El segundo tiene en cuenta la representación pictórica y poé-

${ }^{2}$ Sobre la modernidad dariana y desde perspectivas diversas, son interesantes las aportaciones de Ivan A. Schulman, la de éste con Evelyn P. Garfield, y las de Saúl Yurkiévich, Jesse Fernández y Luis Sáinz de Medrano. 
tica finisecular del mar y la playa, y las diferentes actitudes tomadas por Darío y sorolla. El tercer apartado se centra en el comentario de la representación de ese mismo espacio marino en la obra poética de Darío, como ejemplificación de esa reflexión metafísica de carácter existencial diferente a la modernidad socioeconómica de la pintura de Sorolla. El análisis textual de los paradigmas líricos de la escritura dariana servirán como base empírica para mostrar las variantes respecto a la representación pictórica sorolliana, al tiempo que permitirán destacar la vigencia poética existencial del signo marino ${ }^{3}$.

\section{FIN DE SIGLO, MODERNISMO Y MODERNIDAD}

La delimitación de los caminos que en el ámbito de la cultura hispánica llevan a la modernidad no puede establecerse en términos simples, sino que requiere de una perspectiva completa de todos sus componentes. Como ha escrito Carmen Pena: «En el caso de la modernización de la pintura o del arte de una época, o de un país, ciertas posturas antimodernizadoras explican el sentido particular que adoptó la acción modernizadora» (24). En este sentido, la utilización del espacio marino en la pintura finisecular española de Sorolla y su comparación con el empleo en la poesía modernista hispanoamericana de Darío puede ayudarnos a comprender mejor el sentido de modernidad al que aquí nos referimos. El propio Darío afirmó en «Páginas de arte»: «Se comprenderá la intelectual intimidad que puede nacer entre un pintor y un poeta. Hay mucho de pintura en la poesía, y hay mucho de poesía en la pintura; recordad que, en lineamiento, casi todos los pintores eran poetas, y los que no hacían versos pintaban poemas» (OC, I, 661$62)^{4}$. Las relaciones interdisciplinares entre pintura y poesía (ut pictura poiesis) son, de hecho, constatables en autores modernistas como Julián del Casal o Manuel Machado y fueron después desarrolladas por las vanguardias y algunos del 27 español, desde Gerardo Diego a Rafael Alberti ${ }^{5}$. El

${ }^{3}$ Debe quedar claro desde aquí que no pretendemos identificar modernidad literaria con existencialismo filosófico, ya que son dos cosas claramente distinguibles. Lo que aquí proponemos es identificar la meditación poética sobre la existencia a raíz del espacio marino como uno de los muchos signos de una modernidad artística y espiritual, que trasciende la mera modernidad socioeconómica derivada en los usos contemporáneos del mar y la playa como fenómenos de pasatiempo y asueto social. Véanse al respecto los trabajos de Sergio Rábade (Método y pensamiento en la modernidad, Madrid: Narcea, 1981) y Davis D. McElroy (Existentialism and Modern Literature. An Essay in Existential Criticism, New York: Citadel Press, 1966).

${ }^{4}$ En adelante, todas las citas de Darío se remiten a las Obras completas (OC), indicando después el volumen y las páginas. Litvak.

${ }^{5}$ Véanse los estudios realizados por Peter Standish y, de manera particular, por Lily 
concepto de «modernidad» resulta complejo en su delimitación semántica y existen diferentes etapas y claves de la modernidad, estudiadas ya de distintos modos por Matei Calinescu, quien define la modernidad bajo dos modalidades: una de raíz socioeconómica / tecnológica y la otra de base estética / artística (41-2). Ambas nos interesan a fin de establecer una diferenciación entre la poesía modernista (Darío) y los registros pictóricos (Sorolla) condicionados por el proceso de dicha modernidad en el ámbito de la representación del espacio marino. Darío y Sorolla personifican las dos caras de esa modernidad. En el autor nicaragüense encontramos la escritura de un artista rebelde, antiburgués, contestatario, antimercantil, subjetivo $\mathrm{y}$, sobre todo, preocupado y hasta desazonado por una permanente interrogación metafísica de signo existencial. En el pintor percibimos al artista despreocupado por esas cuestiones metafísicas y dedicado a satisfacer los gustos burgueses al hilo de la modernización de las estructuras sociales. La luminosidad de Sorolla contrasta con la oscuridad del cuestionamiento humano, de modo que frente a la modernidad socioeconómica de Sorolla se instala la modernidad artística de Darío como meditación existencial que responde a un sentimiento agónico de vacío y que deriva hacia un cuestionamiento del papel del ser humano en el misterio del universo. Según demostró Octavio Paz, la modernidad literaria y artística hispánica tuvo su origen en el Modernismo y tiene como gran signo la interioridad y la indagación metafísica de carácter existencial. Este concepto de «modernidad existencial» se circunscribe a la tradición secular de la filosofía general de la existencia y no necesariamente debe coincidir de manera exacta, ni siquiera parcial, con los diversos y variados postulados del llamado existencialismo filosófico del siglo $\mathrm{XX}^{6}$. Nuestro interés en la veta modernoexistencial de la poesía de Darío radica en su consideración como «actitud» poética y humana que obedece a una crisis global sobre el sentido de la

\footnotetext{
${ }^{6}$ Tal existencialismo filosófico no es una doctrina uniforme o un sistema perfecto y homogéneo y el abuso que de él se ha hecho como concepto ha devaluado su sentido. Aunque es un fenómeno privativo del siglo XX, aceptaremos que se pueden encontrar elementos existenciales en muchas de las manifestaciones de la cultura universal. Nuestro interés no radica en buscar en el Modernismo, y concretamente en Darío, una anticipación de los variados presupuestos del existencialismo filosófico, sino de mostrar la presencia de una «actitud existencial» en una parte de su poesía con espacios marinos. Hay en Darío un tipo de enfrentamiento subjetivo con todo lo que rodea a la existencia: la autenticidad, la contingencia, la angustia, el dolor, el tiempo, la lucha con Dios, la muerte, la nada o la posible trascendencia. La continuada presencia de esta actitud existencial en Darío la consideramos como uno de los signos de la modernidad. Sobre el existencialismo, véanse: Denis HUISMAN, El existencialismo (Madrid: Acento Editorial, 1999); Walter A. KAUfMANN, ed., Existentialism from Dostoevsky to Sartre (New York: New American Library, 1975); Harold J. BLACKMAN, Seis pensadores existencialistas: Kierkegaard, Nietzsche, Jaspers, Marcel, Heidegger, Sartre (Trad. Ricardo Jordana, Barcelona: Tau Oikos, 1967); Charles Guignon y Derk Pereboom, eds., Existentialism: Basic Writings (Indianapolis: Hackett, 1995).
} 
existencia, y con la consiguiente desorientación del ser humano en el mundo. Tal actitud aflora en el Modernismo y particularmente en Darío, siendo el espacio marino uno de los paisajes donde se lleva a cabo tal reflexión. La referencia a «poesía existencial» no exige aquí de la presentación referencial del extenso cuerpo crítico de postulados filosóficos del llamado existencialismo, pues nuestro objetivo no pretende establecer unos paralelos concretos en términos de causa-efecto, sino ver en el Modernismo una preocupación poético-existencial que resulta moderna ${ }^{7}$. Esa dimensión meditativa sobre la existencia fue uno de los rasgos apuntados por Charles Baudelaire, uno de los primeros teorizadores de la modernidad. Fue precisamente al hilo de unas valoraciones sobre la pintura de Constantin Guys, cuando Baudelaire esbozó, ya en 1863, su propio concepto de la modernidad en la literatura y el arte. En el artículo «Le peintre de la vie moderne», Baudelaire percibió y anunció el talante existencial de la modernidad al representar al artista como ser solitario en medio del gran desierto humano: «ce solitaire (...) toujours voyạgeant à travers le grand désert d'hommes» (1163). Baudelaire, además, concibió la modernidad como ente indefinible pero escindido entre lo efímero, fugitivo (los particulares históricos y de época) y lo eterno, inmutable (los universales estéticos y temáticos). De ahí, consideró el autor francés, que fuera posible hablar de modernidad en el arte de todas las épocas» ${ }^{8}$. La formulación bodeleriana resulta muy iluminadora porque junto al hecho de enfocarse en la modernidad estética / artística, confirma la importancia de la actitud existencial como marca intrínseca del artista moderno. La visión de Baudelaire tiene aquí mayor sentido si pensamos que Darío y los modernistas conocieron y leyeron con avidez al poeta francés, en especial Les Fleurs du Mal (1857).

En el marco de la valoración intrínseca de la modernidad resulta útil

\footnotetext{
${ }^{7}$ Los postulados doctrinales y filosóficos del existencialismo aparecen en el siglo XX y en la filosofía de Martin Heidegger (Sein und Zeit, 1927), Gabriel Marcel (Journal Métaphysique, 1927), Karl Jaspers (Existenzphilosophie, 1938), o Jean-Paul Sartre (L'être et le néant, 1942), entre otros. Pero ya en la filosofía del XIX, en Arthur Schopenhauer, en Sören Kierkegaard, en Friedrich Nietzsche y después en Edmund Husserl, entre otros, se anuncian muchos de esos presupuestos.

${ }^{8}$ En ese artículo, que al final de su vida Baudelaire tituló significativamente «Le peintre de la Modernité», el poeta francés describe al artista y define la modernidad. En la sección cuarta, titulada «La Modernité», afirma Baudelaire: «A coup sûr, cet homme, tel que je l'ai dépeint, ce solitaire doué d'une imagination active, toujours voyageant à travers le grand désert d'hommes, a un but plus élevé que celui d'un pur flâneur, un but plus général, autre que le plaisir fugitif de la circonstance. Il cherche ce quelque chose qu'on nous permettra d'appeler la modernité; car il ne se présente pas de meilleur mot pour exprimer l'idée en question. Il s'agit, pour lui, de dégager de la mode ce qu'elle peut contenir de poétique dans 1'historique, de tirer l'éternel du transitoire. (...) La modernité, c'est le transitoire, le fugitif, le contingent, la moitié de l'art, dont l'autre moite est l'éternel et l'immuable. Il y a eu une modernité pour chaque peintre ancien» (1163).
} 
considerar los planteamientos revisionistas en torno al fin de siglo modernista. Los últimos años han visto una serie de relecturas del Modernismo hispánico concebido como sistema normativo a la luz de los códigos de la modernidad. Después de la crítica de Juan R. Jiménez, heredada por Ricardo Gullón, deben valorarse las opiniones de Octavio Paz, al tener uno de sus ejes fundamentales en la reflexión sobre el sentido de la modernidad, de la cual las vanguardias fueron una suerte de exasperación. Entre la amplia amalgama crítica en torno al fenómeno modernista, una de las vertientes teóricas más fructíferas pone en tela de juicio el discurso crítico monolítico en favor de una reordenación de los nexos de la escritura modernista con el complejo proceso de la modernidad. El cuerpo textual lírico modernista, y en concreto el de Darío, puede así valorarse como uno de los engranajes de la modernidad poética en lengua española. De entrada, el Modernismo sustituye, al tedio romántico por la angustia del hombre contemporáneo y es a esa vertiente lírica a la que volveremos al analizar particularmente la modernidad existencial de Darío. Así es posible entender que el Modernismo dariano trae consigo una poesía que asienta sus bases sobre una visión moderna de la existencia. Desde muy temprano, Federico de Onís relacionó el Modernismo con la modernidad y la crítica ha venido subrayando paulatinamente la necesidad de leer los códigos del Modernismo como sistema bajo la articulación de tal modernidad ${ }^{9}$. En la percepción del Modernismo como fase inicial de la modernidad resta ejemplificar textual y documentalmente dónde radica tal modernidad y los modos en que los modernistas tuvieron conciencia de ella. En este particular, es sintomático que el propio Darío empleara en diversas ocasiones el término «modernidad» y hasta llegara a emparentarlo con lo poético al tratar de uno de sus libros, Cantos de vida y esperanza (1905), del que afirma: «A todo esto agregad un espíritu de modernidad con el cual me compenetraba en mis incursiones políglotas y cosmopolitas» (OC, I, 215).

El concepto de «modernidad» que aquí estamos deslindando respecto a Darío se define paralelamente como oposición a los valores socioeconómicos de la sociedad burguesa y que tan bien representa la pintura de Sorolla. Ya en 1876 el modernista mexicano Manuel Gutiérrez Nájera escribe «El arte y el materialismo», ensayo donde defiende la dimensión espiritual del arte, lejos de la imitación de lo material y del utilitarismo burgués. Lo mismo podríamos decir de buena parte de la obra de los primeros modernistas, como los cubanos José Martí y Julián del Casal, o el colombiano

\footnotetext{
9 «Nuestro error - afirmó Onís- está en la implicación de que haya diferencia entre 'modernismo' y 'modernidad' porque modernismo es esencialmente, como adivinaron los que le pusieron ese nombre, la busca de la modernidad» (625). La misma idea respecto a las relaciones entre Modernismo y modernidad ha venido repitiendo un amplio sector crítico que ha tenido en los libros de Cathy L. Jrade (1998) y Anthony L. Geist sus últimas expresiones.
} 
José Asunción Silva, enemigos todos de la materialización del arte y del positivismo. En el caso de Darío, Ángel Rama ya estudió con perspicacia la circunstancia socioeconómica del arte modernista. Bastaría traer a colación un relato como «El rey burgués», de 1887, donde Darío representa alegóricamente la muerte de un artista, esclavo de una sociedad materialista regida por la burguesía. También hacia 1895 , y en una crónica de la época porteña, Darío comenta una de las telas del pintor argentino Ernesto de la Cárcova y censura el mundo de espaldas al arte. Darío apunta directamente a «el odio innato de todo intelectual al entronizamiento del mercantilismo imbécil, del gordo becerro burgués fatal a los espíritus de poesía y ensueño» (OC, IV, 850). En el libro primero de La caravana pasa (1903), Darío reincide en los males del utilitarismo: «La época actual ha bastardeado las cosas del espíritu y del entendimiento y del corazón. El utilitarismo y la poca fe han mermado el soñar y el sentir. La vieja lira se ha vuelto un instrumento que hay que poseer a escondidas» (OC, III, 614). Interesa también destacar las quejas de Darío al hilo de sus crónicas artísticas. En «Una exposición», crónica escrita en 1899 e incluida después en España contemporánea (1901), Darío se lamenta: «Los pintores no hallan qué hacer, y desde luego, con singulares casos en contrario, arte no hacen. (...) Escasos, muy escasos, son aquí los artistas que tengan de qué vivir; los ricos son señalados. Por tanto, la lucha por la peseta es ante todo. (...) Se pinta como se escribe, como se esculpe, con la puntería puesta al cocido patrio, buscando la manera de 'reússir', de caer en gracia al público que paga» (OC, III, 172). En los juicios darianos sobre el pintor belga Henri de Groux, incluidos en Opiniones (1906), Darío vuelve a recalcar el rebajamiento artístico de la época y el imperio de la mediocridad a expensas de una economía de mercado. De la vida artística de Groux, a quien conoció personalmente, Darío subraya «la dolorosa esclavitud de un artista selecto que tiene que padecer horribles promiscuidades y la tiranía del industrialismo, las injusticias de la crítica, que no señala al éxito sino al que la paga» (OC, I, 390). Lo mismo podría decirse de las páginas que Darío dedicó en recuerdo de otros pintores, como el mexicano Alfredo Ramos Martínez, cuya figura encarna el verdadero artista y a partir de lo que puede inferirse en Darío su visión del arte y de la modernidad ${ }^{10}$. Darío, en definitiva, se lamenta de una modernización de espaldas a los problemas de la existencia y reclama un espacio para el arte y la poesía. De ahí que afirme al final del prólogo de El canto errante (1907): «La poesía existirá

${ }^{10}$ En «Un peregrino del arte», incluido en «Páginas de arte», Darío afirma: «Hay que saber que Ramos no copia, sino interpreta; es decir, que no sigue a los fotógrafos patentados, a quienes oficialmente se conceden medallas en los salones. (...) Ramón es un puro pintor de la tradición velasquina-rembrandesca, es decir, de los que encuentran la poesía en las cosas mismas, y buscan en cada cosa que pintan la 'psicología', ya sea una persona, o un paisaje, o una flor» (OC, I, 662-63). 
mientras exista el problema de la vida y de la muerte. El don de arte es un don superior que permite entrar en lo desconocido de antes y en lo ignorado de después, en el ambiente del ensueño o de la meditación» (OC, V, 960). También en su crónica «El pueblo del Polo», de Letras (1911), es comparable su actitud al afirmar: «El progreso moderno es enemigo del ensueño y del misterio, en cuanto a que se ha circunscrito la idea de utilidad. Mas, no habiéndose dado un solo paso en lo que se refiere al origen de la vida y a nuestra desaparición en la inevitable muerte, el ensueño y el misterio permanecen con su eterna atracción» (OC, I, 545). Todas estas valoraciones permiten acercarnos a la doble visión que de la modernidad estamos apuntando y que se configura en la veta existencial de la poesía de Darío y en la pintura marina de Sorolla.

\section{DARÍO FRENTE A SOROLLA}

La displicencia dariana y modernista ante el materialismo burgués choca frontalmente con la general aceptación que es visible en la pintura española finisecular, especialmente en Sorolla. Las diferentes etiquetas, tendencias, personalidades y estilos que se entremezclaron bajo el genérico título de pintura española de fin de siglo (pintura realista, naturalista, simbolista, impresionista...) dificultan la codificación de un panorama aclarador. Sin embargo, en el caso español es visible la pervivencia de una corriente dominante de realismo artístico que reflejaba los valores ideológicos del pensamiento burgués y que tiene en el impresionismo una extensión y/o variedad refinada. Contra esas corrientes de captación instantánea, conformadas también en términos naturalistas, respondió un sector artístico español, espoleado por la impronta del movimiento simbolista europeo. Desde Francia, y ya desde 1886 Jean Morèas, Albert Aurier y Maurice Denis habían afirmado el triunfo de la belleza y el ideal sobre la mentira realista. En España, dicha corriente llega muy tímidamente al «modernisme català» y constituye uno de los fundamentos de la poética que configuró el Modernismo hispánico y en el que se enmarca Darío. Así pueden explicarse los entusiastas comentarios de Darío sobre Santiago Rusiñol en España contemporánea (1901), y su mutuo acuerdo en la visión del arte como algo superior, encaminado a la belleza a través de la meditación sobre lo trascendente. Sin embargo, y como ha demostrado Francisco Calvo Serraller, «la corriente del idealismo-simbolismo español se decantó en la primera década del siglo y no tuvo una proyección significativa en el panorama cultural de nuestro país hasta fechas posteriores» (1998: 34). Varios representantes del Modernismo literario hispánico, como Darío o Valle-Inclán, constituyen ejemplares valedores y comentaristas de esa nueva estética simbolista. Darío lo hace a través de su poesía y sus todavía hoy poco 
estudiadas páginas de crítica artística, donde desde muy tempranamente se lamenta de la falta de una base cultural en España y de un público amplio y receptivo. Valle-Inclán lleva a cabo su ideario no sólo ya mediante su propia estética creativa y su tertulia pictórica del Nuevo Café de Levante desde 1903 a 1916, sino sobre todo en La lámpara maravillosa (1916), fundamental tratado estético para comprender el simbolismo artístico español.

En este difuso marco de la pintura española de entresiglos, encontramos abundantes ejemplos de la representación del paisaje marino. Sorolla supo desde el principio que uno de los espacios propios de la modernidad pictórica lo constituía la playa como nuevo hábitat de relación festiva con el mar. Uno de los signos que a inicios de siglo acompañó al advenimiento de la modernización industrial en la vida española fue la concurrencia pública a playas y ciudades costeras del litoral cantábrico (Santander, San Sebastián) y mediterráneo (Valencia). Si los paisajes pictóricos de las marinas habían sido un tema clásico ya desde el siglo XVII, los lienzos que adoptan el mar como pretexto plástico encumbran otras intenciones ligadas precisamente a la modernidad socioeconómica. Sin olvidar la representación del mundo de la pesca, muchos de los pintores españoles, y Sorolla a su cabeza, perfilan la aparición en escena, gracias al mar y la playa, de otros personajes infantiles y femeninos que gozan al aire libre del paulatino cambio de usos y costumbres. Los baños de ola y el lucimiento de pamelas o parasoles pasan a ser recogidos por las telas de muchos pintores españoles de la época: Hermen Anglada Camarasa, Aureliano Beruete, Darío de Regoyos, José Pinazo, Cecilio Plá y, sobre todo, Sorolla. Precisamente, a finales del año 2000 se expuso en Madrid una interesante galería al cuidado de la comisaria Lily Litvak, donde se reunía una colección pictórica marina de sesenta y ocho lienzos y ochenta y tres tablas, así como un total de noventa y ocho ilustraciones publicadas en la prensa madrileña de la época. Entre todos esos pintores de los albores del nuevo siglo XX fue Sorolla quien de forma más recurrente se centró en el espacio marino, al tiempo que fue él también el primer pintor del siglo XX con verdadera proyección internacional.

Una revisión del espacio marino en la pintura de Sorolla favorece la interpretación de su obra como la búsqueda de un mayor protagonismo para Valencia, entonces parte periférica de España. Según ha valorado acertadamente Carmen Pena, las telas de Sorolla llegaron a ser las más populares y sirvieron como representación internacional de la imagen de España hasta el punto de que el mismo Sorolla «aprovechó su éxito y el de su estela para hacerse fuerte en la política artística institucional y nacional a nivel estatal» (22). Sabemos que Sorolla gozó de un enorme éxito, razón que explica las elevadísimas cotizaciones para sus cuadros en el panorama artístico español de entonces. Ninguno de los otros autores de prestigio, ni 
Ignacio Zuloaga ni Hermen Anglada Camarasa, habían podido alcanzar tales fortunas a raíz de sus cuadros. Sorolla, además, tuvo detrás un apoyo constante por parte de importantes figuras del momento, como el doctor Simarro y Blasco-Ibáñez, autor éste cuyas novelas aparecieron algunas veces con dibujos del propio Sorolla y cuyas relaciones con el impresionismo pictórico y con la temática social de Sorolla ya fueron estudiadas por Michael Gerli y Emilio González. Después de unos comienzos en el género histórico, Sorolla cultivó el retrato y los paisajes regionales, pero es en el espacio marino donde Sorolla alcanza sus más singulares ejemplos en telas de la primera década del siglo como Después del baño (1902), Verano (1904), Niños tomando el baño (1905), Nadadores, Jávea (1905), Niños en la playa (1910), y una serie de cuadros ligados ya desde tiempo atrás con el tema de la pesca, como en las piezas Componiendo la vela o El almuerzo a bordo, telas éstas que Darío conoció en una exposición madrileña en 1899 y sobre las que escribió sus impresiones, según detallaremos. Resulta incuestionable el logro sorolliano de las figuras en movimiento, los matices del cabrilleo del sol sobre la orilla del mar y todo lo que en la pintura española se entiende como luminismo ${ }^{11}$. De hecho, la fama de Sorolla llevó a que la Hispanic Society of America de Nueva York expusiera su obra al calor del mecenazgo de Archer M. Huntingon, quien curiosamente fue también amigo y admirador de Darío en el viaje de éste a la capital neoyorquina en 1915. Del 4 de febrero al 9 de marzo de 1909 Sorolla expuso trescientos cincuenta y seis lienzos en la sede de dicha sociedad, ubicada en el West Broadway de Nueva York, y se publicó un catálogo en dos volúmenes que incluía, además, ocho ensayos críticos de la pintura de Sorolla. En uno de ellos, a cargo de Christian Brinton, son destacables algunas observaciones que pueden ayudarnos a deslindar la visión que del espacio marino como modernidad tuvo Sorolla. Para Brinton, «Sorolla seems to have been one of those positive spirits who are predestined to take a definite view of actuality» (414); y unas páginas después reitera: «he knows but one lesson and that is the lesson of actuality» (432, subrayados nuestros). Brinton, por tanto, vio ya la pintura de Sorolla como algo actual, es decir, coetáneo y de acuerdo con una rugiente actualidad: las playas españolas rebosantes de una clase burguesa que encuentra en el mar y la playa una moda estival. En este sentido, una mirada atenta a la representación que Sorolla hace del paisaje marino ratifica esa idea de actualidad y responde a una idea de modernidad diferente a la que hallaremos en el ámbito existencial de la poesía de Darío, según mostraremos. Así se explica también que el mismo crítico Brinton echara en falta esa dimensión filosófica y meditativa en Sorolla, aunque lo disculpara en la idiosincrasia espa-

${ }^{11}$ Para un recuento crítico de la vida y el arte de Sorolla son recomendables los libros de Pantorba y Muñoz. 
ñola ${ }^{12}$. El mismo intento de justificación que un crítico como Brinton llevó a cabo en torno a la ausencia de un arte trascendente en Sorolla reafirma nuestra hipótesis de que la visión del arte y, particularmente, del espacio marino de Sorolla se ubica en una modernidad amparada en la circunstancia socioeconómica del mercado de la oferta y la demanda y adaptada a la circunstancia periférica española. Como ha escrito Carmen Pena al referirse a los centros artísticos de la España de la época, «estos centros iniciaron una vía de modernidad plástica alentada tanto por el afán diferencial como por el empuje económico y social de los mismos» (24). En ese empuje, Sorolla observa que su éxito radica en la satisfacción de los gustos burgueses y que es a ellos a quienes tiene que agradar, tal y como ha escrito Javier Pérez Rojas: «Sorolla es para los valencianos el artista moderno que les descubre una nueva manera de ver su propia tierra. Su pintura es para muchos el modernismo, lo moderno, lo nuevo. Sorolla y los valencianos descubren el paisaje de la luz, en el que el dramatismo y los sentimientos trágicos no tienen cabida» (170). La visión de Sorolla es perceptible en otros de sus seguidores, como el también valenciano Cecilio Plá, pintor de lugares veraniegos levantinos, como la playa de Las Arenas, según muestran, por ejemplo, sus óleos sobre lienzo en Cuatro apuntes de la playa de Valencia (1918). Plá capta grupos de figuras humanas y panorámicas de la playa que plasman el instantáneo bullicio vitalista y luminoso de familias burguesas disfrutando de un día de playa.

Frente al gusto pictórico de Sorolla y sus seguidores por presentar un espacio libre y alejado de toda concepción angustiada del mundo, interesa ahondar en la otra cara de este espacio marino: el que ofrecen Darío y los poetas modernistas como testimonio y punto de partida de una honda reflexión metafísica de carácter existencial. En ella se perfila la pieza clave del rompecabezas modernista como abismo ontológico y espiritual que coincide con la crisis finisecular de las estructuras sociopolíticas en boga. Sobre las ruinas de la edificación romántica, de la que el Modernismo es en buena medida una extensión con nuevos tintes y renovados materiales lingüísticos, los poetas modernistas interpretan la vida bajo una cosmovisión eminentemente subjetiva que mira a la existencia propia. Bajo la herencia del irracionalismo filosófico decimonónico, Darío y los modernistas adelantan algunas de las claves de la reflexión existencial contemporánea: la angustia ante la existencia como dialéctica vida-muerte, el dolor ante la temporalidad, la soledad del ser humano, el problema divino, la muerte en

\footnotetext{
${ }^{12}$ Según Brinton: «There has never been and there can never be anything speculative or philosophical in the art of the Iberian Peninsula (...) The eye, rot the mind, is the controlling factor in all this work» (437). Unas páginas después aseguraba el mismo crítico: «It is unnecesary in the art of Señor Sorolla to seek the profound, the abstract, or the analytical» (450).
} 
su doble matiz de aceptación y angustia, la nada y el no ser, la muerte como nada o la trascendencia. Es en esa orfandad vital y esencial del poeta modernista, y particularmente de Darío, donde cabe explicar las «entrañas del vacío» de las que han tratado Ivan A. Schulman y Evelyn P. Garfield, la «tragicidad» de la que ha hablado Ignacio M. Zuleta (31), y la meditación existencial que también han hallado José $\mathrm{O}$. Jiménez y Carlos $\mathrm{J}$. Morales en la prosa modernista (26). Es ahí también donde podemos considerar la poética modernista como testimonio (pre-)existencial. La representación lírica que el Modernismo poético lleva a cabo del espacio marino confirma que estamos ante uno de los lugares donde se produce una reflexión ante los problemas trascendentes de la existencia humana.

En esta vertiente de reflexión sobre el sentido de la presencia humana en el mundo es donde Darío y los modernistas apuntan directamente a la modernidad de signo existencial. Es ahí también donde podemos encontrar las razones por las que autores de la órbita modernista como Valle-Inclán, Darío y hasta Unamuno censuraron la pintura de Sorolla, mientras otros autores como Blasco-Ibáñez lo apoyaron desde su filiación social y realista-naturalista. $\mathrm{Al}$ margen de las conocidas polémicas con Ignacio de Zuloaga (reunidas en 1998 en una exposición madrileña ${ }^{13}$ ), bastaría recordar las constantes acusaciones de superficialidad y comercialización que se repitieron contra Sorolla por parte de Unamuno, algunos noventayochistas y, en especial, Valle-Inclán, críticas de las que dio cuenta Francisco Calvo Serraller ${ }^{14}$. Estas actitudes opuestas al arte pictórico de Sorolla son visibles también en Darío, cuya obra trasciende lo poético y se planta por vía de la crónica en el terreno de la crítica artística. Al tratar de la oposición modernista al utilitarismo tuvimos ocasión de ver algunas instancias en que Darío enjuició el arte y la pintura de su época ${ }^{15}$. El prestigio de Sorolla no podía pasar desapercibido para Darío y es interesante acercarse a lo que del pintor valenciano escribió Darío y que, sin ser mucho, es significativo. Sus juicios se reúnen en España contemporánea (1901) y así, por ejemplo, al censurar la falta de apoyo gubernamental y privado al arte español, Darío confirma la excepción con la popularidad de Sorolla entre las clases pudientes: «En la última exposición fue de gran resonancia la compra de un

\footnotetext{
13 «Sorolla, Zuloaga: dos visiones para un cambio de siglo». Madrid, 8 de abril-28 de junio de 1998. El catálogo de la exposición se publicó ese mismo año en Madrid por la Fundación Cultural Mapfre Vida.

${ }^{14}$ Para las relaciones de Juan R. Jiménez con Sorolla, véase el trabajo de Guyot.

${ }^{15}$ El interés de Darío en materias de arte y pintura puede comprobarse en muchos textos como los juicios publicados entre 1893 y 1897 en Buenos Aires: «Artistas argentinos»(OC, IV, 849-54), «Notas de arte» (OC, IV, 902-07) o «Exposición de arte latino» (OC, IV, 907-13). También resulta iluminadora al respecto la sección entera de «Páginas de arte» (OC, I, 625-734), muchas páginas de España contemporánea (1901) y del diario de Italia en su visita a la pinacoteca de Turín (OC, III, 509-16), o textos como «En el Louvre» (OC, II, 547-48), de Todo al vuelo (1912).
} 
cuadro de Sorolla hecha por una dama de la aristocracia» (OC, III, 317). Sin embargo, Darío siente que tal fama no se corresponde con los méritos artísticos y así en aquel mismo libro, bajo la crónica «Certámenes y exposiciones», escrita el 7 de abril de 1900, Darío da cuenta del Salón Amaré de Madrid y afirma sin reparos: «Del célebre Sorolla hay también dos telas en las que, como siempre, prueba su vasto dominio de la pintura y $s u$ indigente comprensión del arte» (OC, III, 372, subrayados nuestros). La visión de la modernidad artística de Darío, por tanto, se diferencia de la de Sorolla y esto es aún más notable si pensamos que unas páginas antes de esa misma crónica, Darío había escrito sobre Carlos de Haes, pintor hispano-belga fallecido en 1898. En sus elogios se puede inferir, por un lado, el interés de Darío por las telas marinas y, sobre todo, el ataque a Sorolla y sus seguidores a partir de la referencia dariana a las «paletas apopléticas» $\mathrm{y}$ «las atronadoras murgas coloristas» (OC, III, 370). Darío menciona después directamente a Sorolla como enemigo del arte, según indicamos, y donde lo opone al pintor Raurich, en quien observa «una visión íntima del espíritu de la naturaleza, que tiende a manifestarse con el espíritu del artista» (OC, III, 373). Por último, Darío cierra su crónica con la sutil afirmación de que la fama nacional no supone la genialidad en el arte con lo que nuevamente apunta no sólo el retraso pictórico español, sino sus claras diferencias artísticas con Sorolla cuando afirma: «Los pintores españoles que ciertamente valen - con las excepciones consiguientes- venden en Europa mismo o en los Estados Unidos. Esos son los que buscan sendas no usadas de bello arte, y que, por lo general, no gustan en su país» $(\mathrm{OC}, \mathrm{I}, 373)^{16}$. Darío reconoce la riqueza y el esplendor solar de la pintura de Sorolla, a quien cita también en su crónica «Una exposición», incluida en España contemporánea (1901). Sin embargo, Darío echa de menos el mundo interior de la pintura española de fin de siglo, y particularmente de Sorolla ${ }^{17}$. Tanto es así que Darío llega incluso a comentar dos telas marinas de Sorolla que considera meritorias: las tituladas Componiendo la vela y El almuerzo a bordo. Sin embargo, aunque Darío destaca el mérito en las condiciones de color y en el dibujo, ambas ejemplifican la falta de un

${ }^{16}$ Un historiador de la pintura de la época como Francisco Calvo Serraller ha escrito respecto a la modernización artística española: «No es difícil comprobar que el panorama artístico español vivía de espaldas a la realidad internacional más dinámica en este campo, cuyas modas llegaban siempre con varias décadas de retraso» (1993: 35)

17 Darío afirma: «Después de recorrer estos salones diríase que para los pintores españoles no existe el mundo interior. El mismo paisaje no es sino la reproducción inanimada de tierra, de árboles, de aguas, solitarios o con acompañamiento de figuras anecdóticas, sin que la secreta vida de la Naturaleza se presente una sola vez, y mucho menos el alma del artista, que contagiara con su íntima sensación al espectador atraído» (OC, III, 176). 
espíritu trascendente en favor de una mera copia de lo que Darío llama la «inevitable realidad» ${ }^{18}$.

Frente a la luminosidad y la placidez de la pintura marina de Sorolla, bastaría acudir a la meditación existencial que revelan muchas de las preguntas metafísicas que otros poetas y prosistas del Modernismo establecieron en diversos textos al hilo del espacio marino. Piénsese, por ejemplo, en algunos de los textos de Manuel Gutiérrez Nájera incluidos en el póstumo Poesías (1896). Así, el poema «A un triste», colocado curiosamente en la sección pictórica «Odas breves», presenta al yo poético en una solitaria playa desde donde contempla el paso de la barca del amor y desde donde reflexiona sobre el sentido de la existencia. En «Para entonces», Gutiérrez Nájera plantea un hondo poema que es el deseo de morir en juventud y en un atardecer junto al mar. Lo mismo puede decirse del empleo que hace el cubano Julián del Casal del espacio marino como marco de reflexión existencial en el poema «Día de fiesta», de Nieve (1893). Algunas de estas actitudes están ya anunciadas en algunos románticos y en varios de los llamados «premodernistas» españoles, que hábilmente ha sabido reconfigurar Richard A. Cardwell. Cabría mencionar aquí la poesía marina insular de Tomás Morales y Rafael Romero («Alonso Quesada»). Resulta obvio señalar que los poetas del Modernismo hispánico habían aprendido mucho del contenido meditativo del espacio marino en la poesía romántica de un autor como Baudelaire, en quien cabría rastrear muchos ejemplos sólo en Les Fleurs du Mal (1857) («L'Homme et la Mer», «Un voyage à Cythère», «L'Albatros»...). Lo mismo podríamos indicar en «L'Éternite» de Arthur Rimbaud, o en la idea del cementerio marino de Paul Valèry. Pero en la poesía moderna en lengua española, Darío y Rosalía de Castro fueron quien de forma más honda y pionera establecieron una formulación meditativa existencial a partir del espacio marino. En el caso de la autora gallega, así lo demuestran muchos de los poemas de En las orillas del Sar (1884). Basta leer las composiciones que comienzan «Del mar azul las transparentes olas...», «Sedientas las arenas...» o en el poema número XLII, donde la gallega identifica su pensamiento de duda y pesar con la hondura del mar. Esto también ocurre en algunos de los textos poéticos de Antonio Machado, quien en «Glosa» (poema LVIII), por ejem-

18 «Sorolla - escribe Darío- presenta una tela meritoria, Componiendo la vela, en la cual habría que señalar, al par que las condiciones de color que acreditan a este pintor y su estudio del movimiento, la nimiedad en la rebusca de un efecto como el atigrado de luz y sombra que produce el sol al pasar entre las hojas. Por otra parte, sus figuras, muy bien hechas, tienen ojos que no miran, gestos que no dicen nada; es un mundo de verdad epidérmica, de realidad por encima. Esto mismo digo de los personajes de su escena de mar El almuerzo a bordo: en el ancho bote, bajo las velas, unos cuantos marineros toman su alimento en la fuente común. Maneja Sorolla con habilidad el claroscuro; los tipos están bien agrupados; la inevitable 'realidad' está conseguida» (OC, III, 178-79). 
plo, establece una reafirmación manriqueña de la vida como río hacia la mar de la muerte. De «Proverbios y Cantares» (poema CXXXVI), pueden verse los números XV, XLIV y XLV. También esto es recurrente en «Parábolas» (poema CXXXVII) y en la tercera parte de «Los sueños dialogados» o en «El mar triste» (poema CLXXXV). Y algo similar hallamos en poemas como «Ocaso» o «Marina», de su hermano Manuel Machado. De igual modo, un libro clave para la evolución de la poesía hispánica como fue Diario de un poeta reciencasado (1917) de Juan R. Jiménez, resulta ser un diálogo abierto del poeta con la conciencia del mar y el amor camino de Nueva York. Esta meditación marina juanramoniana llega a los exiliados del 27, como el Pedro Salinas de El contemplado (1946) o la sección «Que van a dar en la mar», de Clamor (1957) de Jorge Guillén, por citar sólo algunos ejemplos de la modernidad del espacio marino como reflexión poética existencial. En el caso particular de Darío todo esto puede comprobarse textualmente al analizar su obra poética completa y a la que seguidamente atenderemos. En suma, lo moderno-existencial del Modernismo y de Darío en particular radica en su visión opuesta a la modernidad socioeconómica que representó la pintura de Sorolla y en el hecho de que muchas de esas preguntas siguen vigentes contemporáneamente en el ámbito de la poesía existencial hispánica del siglo $\mathrm{XX}^{19}$.

\section{EL ESPACIO MARINO COMO MEDITACIÓN EXISTENCIAL DARIANA}

La verificación de nuestra hipótesis inicial debería pasar por el análisis de la obra completa de Darío, pero nuestro análisis se centrará en la obra poética. No pueden dejarse de señalar algunos textos prosísticos que verifican la exploración meditativa de Darío en torno al espacio marino y su abierto enfrentamiento a la modernización industrial. En la prosa poemática, pueden verse, por ejemplo, las diversas meditaciones sobre la existencia por vía de lo femenino, la divinidad o la infancia de «Idilio marino» (OC, IV, 441-42), «Monotonía del mar» (OC, IV, 446) y «En el mar» (OC, IV, 469-70), respectivamente. La prosa de España contemporánea (1901) se abre con la crónica «En el mar», relato del trayecto de Buenos Aires a Barcelona que desde el inicio muestra una dimensión reflexiva ${ }^{20}$. En otro texto de Tierras solares

19 Véanse al respecto los estudios de Francisco J. PEÑAs-BERMEJo, Poesía existencial española del siglo XX (Madrid: Pliegos, 1993) y «El carácter existencial de la poesía de Rubén Darío y su presencia en la lírica española del siglo XX», Alba de América 20-21 (1993): 311-32.

${ }^{20}$ Darío describe el mar y asegura: «Así pienso en tanto se inicia a bordo una existencia de monotonía que conocéis bien los que habéis cruzado el océano» (OC, III, 18). $\mathrm{Y}$ unas páginas después, tras relatar la presencia de un presidiario a bordo, el fatalismo existencial de Dario le lleva a escribir: «Estamos en alta mar; un incendio, un choque, 
(1904), Darío escribe desde la orilla del mar malagueño y muestra sus reticencias sobre el proceso de modernización de la sociedad española, que según él quiebra el arte y la originalidad de lo local y lo pintoresco ${ }^{21}$. Defensor de la modernidad estética, Darío reflexiona unas páginas después sobre su concepción pre-destinada del universo, donde el mar (Thalasa) es parte de la misteriosa armonía universal y donde, como en el orfismo-pitagorismo, todos los seres tienen un alma y una misión ${ }^{22}$. También en la crónica «En Asturias», de Opiniones (1906), Darío se encuentra en las playas cantábricas y allí reitera su disgusto por el advenimiento de una modernización industrial (modernidad socioeconómica) de espaldas al arte, que está en la naturaleza misma (modernidad estética) ${ }^{23}$. Unas páginas después, en esa misma crónica, Darío relata un eclipse solar frente al mar que le vuelve a permitir reflexionar sobre el misterio de la vida ${ }^{24}$.

un naufragio podrían ocurrir, y ese presidiario tiene igual derecho que cualquiera de nosotros para salvar su existencia» (OC, III, 20).

${ }^{21}$ Darío afirma: «El progreso es enemigo de lo pintoresco, y su nivelación no va dejando carácter local ni originalidad en ninguna parte. (...) Los malagueños progresistas que quieren su ciudad igual a no importa qué 'ciudad moderna', con las abominaciones rectangulares que odiaba el gran Yanqui, están en su derecho, como los venecianos que quieren rellenar el Canalazzo y echar al olvido las góndolas. Están en su derecho; pero también están en el suyo los artistas del mundo que defienden la belleza del pasado y la razón del arte» (OC, III, 876-77).

${ }^{22}$ Hablando del mar como Thalasa, escribe: «Ella vive en su misterio. Hace su eterna obra, cumple su destino infinito. Apenas si se comunica con los corazones que se acuerdan con la palpitación del suyo, con las mentes de los soñadores y pensadores que se hunden en lo insondable del tiempo y del espacio, con los buzos de Dios» (OC, III, 890).

${ }^{23}$ Una muestra de la opinión que a Darío le merece tal modernización industrial, y con ella el fenómeno social del turismo, aparece en esta misma crónica. Darío no es anti-moderno, sino que anticipa casi proféticamente las consecuencias de tal modernización: «Esta quietud, esta pasividad, este tranquilo reposo en la naturaleza ha de cambiar con las invasiones de la vida moderna que están transformando a España. (...) Y perderá La Arena su poesía, ¡helás!, y ya habrá aquí veraneantes que pasearán sus modas, y correrán con la playa otros automóviles que los cangrejos, y habrá casino con sus correspondientes petits-chevaux, y los que como yo buscan la actual paz y sosiego que dan estas cosas primitivas se irán con la música y sus sueños a otra parte. Aunque pronto no habrá rincón del mundo en donde refugiarse. La unificación del planeta será absoluta» (OC, IV , 434). Darío se opone a la modernización como forma artificial de quebrantar la naturaleza y su belleza, como cuando satiriza sobre la presencia de unas castas bañistas en la playa: «He advertido que no solamente la robusta y venerable matrona, sino la guapa y gallarda señorita, se enfundan en unos camisones prosaicos que las envuelven desde el cuello a los pies. Al verlas ciertamente, el tritón más salaz recule épouvanté. Mas no percatan las pudorosas damas que las tales túnicas resguardadoras de misterios, una vez que se mojan, se pegan al cuerpo como los paños de los escultores a las estatuas de barro en los talleres, y que la indiscreción de la tela es entonces de una realidad irónica y flagrante» (OC, I, 435).

${ }^{24}$ Darío describe el paso de unas barcas y afirma: «La oscuridad no me dejaba percibirlas. Mas en la consternación de la Naturaleza toda, oía el son del mar como el comentario de un misterioso coro» (OC, I, 450). 
En el ámbito de la poesía, resulta muy iluminador el análisis específico de los libros poéticos completos de Darío. Interesa tener en cuenta aquellos poemas que el propio autor organizó al final de su vida y que han sido recientemente editados bajo el título general de $Y$ una sed de ilusiones infinita. El hecho mismo de que fuera Darío quien elaborara su propia selección poética es razón suficiente para investigar su disposición textual a la luz de los códigos de la modernidad aquí señalados. Es muy significativo que la ordenación de los poemas encaje con unos hilos temáticos que resultan ser parte integral de la meditación contemporánea enmarcada en la modernidad: lo vital, lo erótico, lo existencial, lo religioso, lo social, y todo ello a partir de tratamientos diversos y hasta contradictorios. Nuestro interés radica en algunos de los poemas que el nicaragüense seleccionó como testimonios de un interés por lo marino como espacio de reflexión sobre la existencia. Es precisamente en ellos donde Darío lleva a cabo una poética de cuestionaiento metafísico que resulta ser anuncio de la modernidad por vía de lo existencial. Esto no implica decir que la poesía de Darío coincida necesariamente con los atributos reconocibles en los nombres centrales del existencialismo filosófico del siglo $\mathrm{xx}$ y en sus categorizaciones estudiadas ya por Emmanuel Mounier. Resulta muy significativo que Darío incluyese desde el inicio de su selección $Y$ una sed de ilusiones infinita, algunos de los poemas más significativos respecto al paisaje marino. Tras el introductorio «Preludio» (que es el que se inicia «Yo soy aquel...»), Darío decidió incluir los poemas «Caracol», «Marina» y «El viaje a Citeres». El primero vuelve a mostrar una dimensión del mar como meditación y misterio al escuchar el sonido del caracol: «y oigo un rumor de olas, y un incógnito acento / y un profundo oleaje y un misterioso viento...» (OC, V, 929). El segundo implica un retorno a la infancia y una reflexión sobre la vida a partir del espacio marino. El tercero es una despedida marina que permite al poeta dejar atrás una existencia amarga y llena de desilusiones: «Y en la playa quedaba desolaba y perdida / una ilusión que aullaba como un perro a la Muerte» (OC, V, 853).

Un recorrido diacrónico por la poesía de Darío muestra ese nexo entre el espacio marino y la meditación moderno-existencial. Resulta sintomático que el paisaje marino representado sirva ya al Darío juvenil para enmarcar episodios amorosos que reproducen un desengaño vital. El espacio marino se torna así metáfora del dolor y encuentra todavía resabios románticos, como cuando en «Introducción», de Epistolas y poemas (Primeras notas) (1885), Darío reflexiona: «En tus promesas divinas / no me hablaste de dolores, / ni de sus pintadas flores / me enseñaste las espinas; / bajo las ondas marinas / hay escollos que temer» (OC, V, 393-94).

La utilización del paisaje marino como marco caracterizador de un desengaño amoroso es un recurso que los modernistas tomaron de la tradición romántica y que, por tanto, no puede entenderse como modernidad 
existencial ${ }^{25}$. Darío, sin embargo, percibe el mar fundamentalmente como espacio para la reflexión sobre su propia existencia. En este sentido, es harto significativo que el poeta Juan R. Jiménez, amigo y confidente epistolar de Darío, escribiera un retrato del nicaragüense en Españoles de tres mundos (1942), donde Darío es presentado como un ser íntimamente relacionado con el $\operatorname{mar}^{26}$. Juan R. Jiménez, pese a todo, percibió la íntima comunicación de la existencia dariana con el espacio marino. Este talante que encuentra en el mar un espacio de reflexión sobre la existencia es comprobable en Darío ya desde bien temprano, como en una de las estrofas de «Ignoro de dónde vengo / ni a dónde voy a parar; / he empezado a navegar / ignota playa buscando, / y voy bogando, bogando / sobre las aguas del mar» (OC, V, 395). No resulta difícil ver en estos versos un anticipo de «Lo fatal», de Cantos de vida y esperanza (1905), poema capital del Modernismo en cuanto a la moderna meditación existencial. De forma parecida, el soneto «La dulzura del Ángelus», incluido también en aquel mismo libro, reflexiona existencialmente sobre el sentido de la vida al establecer un metafórico espacio marino: «Y esta atroz amargura de no gustar de nada, / de no saber adónde dirigir nuestra prora, / mientras el pobre esquife en la noche cerrada / va en las hostiles olas huérfano de la aurora...» (OC, V, 898). La angustia ante el destino desconocido constituye la dolorosa realidad del hombre que anticipa su total aniquilamiento, pero que habrá de aceptar por su eterna ignorancia. Estas ideas coinciden con el vacío existencial de poemas como los Nocturnos y el citado «Lo fatal», al tiempo que anuncian unas preocupaciones que desde el Modernismo serán recurrentes en la lírica hispánica posterior. En uno de esos Nocturnos, el que se inicia «Quiero expresar mi angustia...», incluido también en Cantos de vida y esperanza (1905), Darío plantea metafóricamente la vida como viaje marino: «Y el viaje a un vago Oriente por entrevistos barcos» (OC, V, 900). Tras autodefinirse como «huérfano esquife» (OC, $\mathrm{V}, 900$ ), el poeta reconoce su angustia existencial: «Y el horror de sentirse pasajero, el horror // de ir a tientas, en intermitentes espantos, / hacia lo inevitable desconocido y la / pesadilla brutal de este morir de llantos / de la cual no hay más que Ella que nos despertará!» (OC, V, 900).

${ }^{25}$ Como ejemplo de los poemas darianos de corte romántico en el espacio marino, véase el segundo poema de la serie Abrojos (1887) o los textos III y IV de Rimas (Otoñales) (1887).

26 «iCuánto he pensado que Rubén Darío era, no un lobo de mar, un raro monstruo humano marino, bárbaro y exquisito a la vez! Siempre fue para mí mucho más ente de mar que de tierra. (...) Él mismo tenía algo de gran marisco náufrago. Y, sin duda, su instrumento sonoro favorito era el caracol. Su poesía, ¿no es una cantata de caracol y lira? (...) Su misma técnica era marina. Modelaba el verso con plástica de ola» (41-2). Juan R. Jiménez no alcanzó a ver aquí del todo el mar metafísico y psicológico en Darío y lo percibió más en su filiación pagana y parnasiana. 
También en otro poema clave de la poética dariana, el titulado «Coloquio de los centauros», de Prosas profanas y otros poemas (1896), es posible hallar la meditación sobre la existencia en relación con el mar. En boca del mítico centauro Quirón, Darío afirma en términos panteistas su creencia de que todas las cosas tienen un alma: «cada hoja de cada árbol canta un propio cantar / y hay un alma en cada una de las gotas del mar» (OC, V, 796). En las estrofas finales del «Poema del otoño», incluido en el libro homónimo de 1910, Darío redunda en lo mítico y dota al ser humano de una naturaleza marina: «La sal del mar en nuestras venas / va a borbotones; / tenemos sangre de sirenas / y de tritones» (OC, V, 1057). Por eso, en el mismo poema Darío había entrevisto el destino humano en el mar como espacio de eternidad: «y nuestras vidas son la espuma / de un mar eterno» (OC, V, 1053). Darío entronca aquí con el sentido manriqueño de la muerte evocando los ríos como vida que fluyen al mar, en alegórico testimonio del fin de la existencia terrena. Darío se sitúa asimismo ante el mar del ser de Giacomo Leopardi y se aproxima al cementerio marino de Paul Valèry en lo que luego Darío define en términos divinos como «mar de Dios» (OC, V, 1020), en «Libros extraños» de El canto errante (1907). En un texto dariano tan importante como el que se inicia «Yo soy aquel...», que abre intencionadamente la selección de Darío y su libro Cantos de vida y esperanza (1905), hallamos una autobiografía vital y espiritual en la que también aparece una meditación de su dolor por existir a través del símil marino: «Como la esponja que la sal satura / en el jugo del mar, fue el dulce y tierno / corazón mío, henchido de amargura / por el mundo, la carne y el infierno» (OC, V, 863). En otras ocasiones la meditación sobre la insatisfacción del hombre en el mundo no halla una causa concreta, como en «Tarde del trópico», de Cantos de vida y esperanza (1905), donde Darío revela un paisaje marino de duelo, amargura y tristeza que coincide con la visión interior del poeta mismo: «Es la tarde gris y triste. / Viste el mar de terciopelo / y el cielo profundo viste / de duelo» (OC, V, 898). En algunas ocasiones, el espacio marino incluye la visión de elementos que refuerzan la reflexión del poeta, como en el poema «Pájaros de las islas...», nunca incluido en libro poético. Escrito en el invierno mallorquín de 1906, Darío evoca el paisaje isleño para comprender el misterio del mundo a través del vuelo de esas aves: «Pájaros de las islas, ¡oh pájaros marinos!, / vuestros revuelos, con / ser dicha de mis ojos, son problemas divinos / de mi meditación. / Y con las alas puras de mi deseo abiertas / hacia la inmensidad, / imito vuestros giros en busca de las puertas / de la única Verdad» (OC, V, 1326). El vuelo de estas aves marinas evoca el de aquellos otros albatros en el poema de Baudelaire «L'Albatros», de Les Fleurs du Mal (1857), donde se simboliza el esfuerzo inútil del poeta en una sociedad que lo rechaza. También Darío reincide en esa importante idea dentro del Modernismo al presentar a los poetas en «iTorres de Dios! 
¡Poetas!», de Cantos de vida y esperanza (1905), como seres necesariamente obligados a afrontar las iras de una sociedad de espaldas al arte. De nuevo, los poetas se ubican en un paisaje marino al ser una suerte de torres divinas, «rompeolas de las eternidades!» (OC, V, 880), con la capacidad de poner ante cualquier afrenta «una soberbia insinuación de brisa / y una tranquilidad de mar y cielo» (OC, $\mathrm{V}, 881)$.

El espacio marino sirve con frecuencia a Darío para poetizar lo que Enrique Anderson-Imbert calificó de «angustiosas interrogaciones del enigma del ser» (169). Así ocurre en el poema «Revelación», de El canto errante (1907), donde hay una suerte de revelación divina en el acantilado de una roca marina. La visión sobrenatural del poeta tiene como testigo al mar que recobra su mitológica condición femenina y maternal cuando Darío afirma: «...Y mi deseo / torno a Thalasa maternal la vista, / pues todo hallo en la mar cuando la veo» (OC, V, 978). En otras composiciones, el mar da pie a unas ideas enmarcadas en la reencarnación y que pertenecen al esoterismo y al ocultismo. Especialmente revelador en este particular es el poema «Eheu!», incluido también en El canto errante (1907). Se trata de un texto plagado de «abismos» existenciales, palabra que, en su intento de autoconocimiento personal, emplea literalmente el propio Darío junto a los atributos del «yo y el no yo», «del ser y el no-ser», así como los «fragmentos de conciencias / de ahora y ayer» (OC, V, 1010-11). «Eheu!» plantea la reflexión del poeta que frente al paisaje marino se siente un ser reencarnado que desde su antigüedad cuestiona su finalidad en el mundo: «Aquí, junto al mar latino, / digo la verdad: / siento en roca, aceite y vino / yo mi antigüedad. / Oh, qué anciano soy, Dios santo, / oh, qué anciano soy!... / ¿De dónde viene mi canto? / Y yo, ¿adónde voy?» (OC, V, 1010). El interés de Darío por lo órfico-pitagórico le llevó a introducirse en las doctrinas de la transmigración de las almas ${ }^{27}$. Conciliando lo católico con lo teosófico, Darío creyó firmemente en la reencarnación, como ya señaló Carthy L. Jrade (1983: 71-2). Las menciones de esta transmigración de las almas en el espacio marino prueban otra vez la reflexión existencial que la poética dariana llevó a cabo al hilo de tal paisaje. El canto errante ofrece

${ }^{27}$ Según tales doctrinas, el alma procede de otro mundo y manchada con el pecado debe llevar, encadenada al cuerpo, una vida de peregrinación hasta que logre verse libre de lo sensual en favor de lo espiritual. Darío, igual que los órficos, consideró al alma un espíritu desterrado en este mundo como castigo de una culpa anterior heredada. Uno de los mejores biógrafos de Darío, Edelberto Torres, señala cómo el poeta trabó amistad con el doctor G. Encausse («Papús»), gallego afincado en Francia y autor de varios trabajos sobre el ocultismo y la reencarnación, y quien reconoció en Darío a un antiquísimo espíritu, en su último avatar. Las obras de G. Encausse han sido traducidas al español. Véanse: El ocultismo (Madrid: Edaf, 1985), y La reencarnación (Madrid: Edaf, 1985). Otras obras y autores ocultistas que Darío conoció son Helena P. Blavatski y Edouard Schuré, autores de fundamentales estudios teosóficos. Véase el capítulo XLVI de la Autobiografía (1912) de Darío (OC, I, 133-34). 
pruebas de todo esto, como en la «Epístola a la Sra. de Lugones», escrita en el mar Mediterráneo y desde donde Darío reconoce: «Hay en mí un griego antiguo que aquí descansó un día / después que le dejaron loco de melodía / las sirenas rosadas que atrajeron su barca. / Cuanto mi ser respira, cuanto mi vista abarca, / es recordado por mis íntimos sentidos: / los aromas, las luces, los ecos, los ruidos, / como en ondas atávicas me traen añoranzas / que forman mis ensueños, mis vidas y esperanzas» (OC, $\mathrm{V}$, 1028-29). En el mismo libro se halla el poema «Retorno», que constituye una reafirmación del paisaje marino como marco para la meditación sobre el misterio de la existencia y también de las vidas pasadas: «Por atavismo griego o por fenicia influencia, / siempre he sentido en mí ansia de navegar, / y Jasón me ha legado su sublime experiencia / y el sentir en mi vida los misterios del mar» (OC, V, 1066). El espacio marino del Mediterráneo reaparece en "Valldemosa», incluido después en Canto a la Argentina y otros poemas (1914), y donde hallamos otra evocación de posibles vidas pasadas en las civilizaciones grecolatinas.

Los poemas señalados ejemplifican en Darío un tratamiento del espacio marino desde una desorientación ontológica que deriva en una angustiada reflexión existencial. Así lo reconoce Darío en Historia de mis libros (1909), donde afirma: «Ciertamente en mí existe, desde los comienzos de mi vida, la profunda preocupación del fin de la existencia, el terror a lo ignorado, el pavor de la tumba, o, más bien, del instante en que cesa el corazón su ininterrumpida tarea y la vida desaparece de nuestro cuerpo» (OC, I, 223). Es así que los poemas aquí aducidos comparten un mismo vínculo respecto a la visión del mar como objeto de reflexión y no de mera representación realista y/o impresionista de un espacio social y burgués de diversión. La reflexión que revelan tales textos son signos inequívocos de una modernidad artística, opuesta a la modernidad socioeconómica, ausente de preocupación existencial, que respira la pintura marina de Sorolla y su voluntad de satisfacer los gustos del público burgués.

\section{CONCLUSIONES FINALES}

Teniendo en cuenta la inclusión de muchos de los poemas comentados dentro de la referida selección dariana, y a partir de las consideraciones teóricas y prácticas realizadas en este estudio, podemos concluir validando nuestra inicial hipótesis de las dos visiones del espacio marino como modernidad perceptibles en la poesía de Darío y en la pintura de Sorolla. Creemos haber demostrado que en la poesía de Darío se halla la otra cara de la moneda respecto a la pintura de Sorolla. La modernidad socioeconómica de Sorolla se plasma en una pintura placentera, realista y burguesa del espacio marino. La poesía de Darío apunta hacia una búsqueda y conquis- 
ta de la modernidad estética que abarca la poetización de los problemas generales de la existencia y que se opone a la visión de la modernidad socioeconómica. El posicionamiento burgués ante la vida, tendente al simple goce y ajeno a cualquier profundización existencial, prefiere la luminosidad recogida en las playas y las arenas de muchos de los lienzos de Sorolla a las oleadas trágicamente existenciales de los mares del ser planteados en la lírica de Darío. La gozosa luz valenciana plasmada por Sorolla se contrapone al hondo cuestionamiento modernista, y dentro de él también a la contraimagen de la España trágica que muchos autores del llamado 98, desde Baroja a Unamuno, fueron hilando paulatinamente en algunas de sus mejores páginas. Por todo ello, la modernidad de la pintura de Sorolla radica en la representación de un paisaje que el siglo XX irá tomando después como forma estival de vida y asueto y que coincide con los avances que en materia económica y social implicó la modernización industrial. Pero se trata de una modernidad que, al margen de los logros en la disposición de figuras y dibujos, colores y matices, cabe valorar más con una finalidad socioeconómica que artística. El público burgués que compra las telas de Sorolla halla en esos cuadros una forma de ostentación y lujo, a la vez que ve en las playas allí representadas la reivindicación de un regionalismo periférico ${ }^{28}$. La modernidad de Darío, en cambio, traspasa cualquier idea de arte restringido a lo regional o periférico y busca su dimensión universal como expresión de la belleza y como anhelo de la armonía universal. En esa búsqueda se produce el choque con la realidad y el vacío del hombre y del artista ante una sociedad de espaldas al arte y ante una existencia inexplicable. Darío, como los simbolistas, perfila la modernidad de la meditación existencial por vía del arte y recala doblemente en la dimensión formal y en la conceptual: en el logro de una canalización expresiva renovadora para la lírica hispánica posterior y en el desarrollo de unas inquietudes existenciales que habrán de recorrer algunas de las mejores páginas de la poesía hispánica de todo el siglo XX, desde Unamuno a Vallejo, y desde Machado a Paz.

Nuestra hipótesis en torno a las diferencias entre Darío y Sorolla, así como sus modos de percibir el arte y la modernidad se ratifica en el hecho de que la pintura del levantino desembocó, por lo general, en un regionalismo que resultó ser prolongación del costumbrismo decimonónico, y que tuvo también su paralelo en poetas regionales como Vicente Medina. El mismo Sorolla se incorporó claramente a esa dinámica regionalista pintando después, entre 1911 y 1919, y por encargo de la Hispanic Society of America, todo el carácter regional y periférico español. La obra literaria

\footnotetext{
${ }^{28}$ Carmen Pena escribe respecto a los centros periféricos peninsulares, siendo uno de ellos el levantino: «lo cierto es que estos centros iniciaron una vía de modernidad plástica alentada tanto por el afán diferencial como por el empuje económico y social de los mismos» (24).
} 
de Darío, por otro lado, y su visión del arte por la vía de lo modernoexistencial supuso un nuevo aire para la poesía española e hispanoamericana tanto en la canalización expresiva como en la poetización de unas preocupaciones existenciales. La revisión de estos dos artistas del fin del siglo hispánico y sus distintas concepciones del arte por vía del espacio marino favorecen la comprensión de la modernidad y confirman la necesidad de leer a Darío como uno de los pioneros de la moderna poetización existencial en lengua española.

\section{OBRAS CITADAS}

AA.VV., Centro y periferia en la modernización de la pintura española (1880-1918), Madrid: Ministerio de Cultura, 1993.

ANDERSON IMBERT, Enrique, La originalidad de Rubén Darío, Buenos Aires: Centro Editor de América Latina, 1967.

BAUDElaIRE, Charles, Oeuvres complètes, París: Éditions Gallimard, 1961.

BRINTON, Christian, «Sorolla at the Hispanic Society», Eight Essays on Joaquín Sorolla y Bastida, New York: The Hispanic Society of America, 1909, I, 407-54.

CAlinesCu, Matei, Five Faces of Modernity. Modernism, Avant-garde, Decadence, Kitsch, Postmodernism, Durham: Duke UP, 1991. [Cinco caras de la modernidad, Madrid: Tecnos, 1991].

CALVO SERRALler, Francisco, «Los orígenes de la modernización artística española». AA.VV., Centro y periferia en la modernización de la pintura española (1880-1918), Madrid: Ministerio de Cultura, 1993, 34-39.

-, «El simbolismo y su influencia en la pintura española del fin de siglo», en Paisajes de luz y muerte. La pintura española del 98, Madrid: Tusquets, 1998, 17-54.

-, «Sorolla y Zuloaga: luz y sombra del drama moderno de España», Paisajes de luz y muerte. La pintura española del 98, Barcelona: Tusquets, 1998, 195-232.

CARDWELL, Richard A., «El premodernismo español», Historia de la literatura española, Coord. Leonardo Romero Tobar, Madrid: Espasa-Calpe, 1998, 306-22.

DARío, Rubén, Obras completas, Madrid: Afrodisio Aguado, 1950-53, 5 vols. [OC].

-, Y una sed de ilusiones infinita, Ed. Alberto Acereda, Barcelona: Lumen, 2000.

ELLIS, Keith, Critical Approaches to Rubén Dario, Toronto: U of Toronto P, 1974.

FERNÁNDEZ, Jesse, «La modernidad en algunos textos de Rubén Darío», Estudios críticos sobre la prosa modernista hispanoamericana, Ed. José Olivio Jiménez, New York: Eliseo Torres, 1975, 189-98.

GeIST, Anthony L. y José B. MONLEÓN, eds., Modernism and its Margins. Reinscribing Cultural Modernity from Spain and Latin America, New York: Garland Publishing, 1999.

GERLI, Michael, «Blasco Ibáñez's 'Flor de mayo', Sorolla, and Impressionism», Iberomania 1 (1974): 121-29.

GONZÁLEZ, Emilio, «Bajo la sombra del modernismo y el impresionismo. La generación del 98 y el simbolismo», Ínsula 350 (1976): 11.

Gullón, Ricardo, Direcciones del Modernismo, Madrid: Alianza Editorial, 1990.

GUYOT, Yoelle, «Juan Ramón Jiménez y Joaquín Sorolla (Un artículo poco conocido de Juan Ramón)», La Torre 72 (1971): 118-23.

JIMÉNEZ, José Olivio, «Introducción a la poesía modernista hispanoamericana», Antología crítica de la poesía modernista hispanoamericana, Madrid: Hiperión, 1994, 9-56. 
- y Carlos Javier MoRALES, La prosa modernista hispanoamericana, Madrid: Alianza Editorial, 1998.

JIMÉNEZ, Juan Ramón, Españoles de tres mundos, Buenos Aires: Losada, 1942.

-, El Modernismo. Notas de un curso (1953), Ed. Ricardo Gullón y Eugenio Fernández Méndez, México: Aguilar, 1962.

JRADE, Cathy L., Rubén Dario and the Romantic Search for Unity, Austin: U of Texas $\mathrm{P}, 1983$.

-, 'Modernismo', Modernity and the Development of Spanish American Literature, Austin: U of Texas P, 1998.

LITVAK, Lily, Imágenes y textos: estudios sobre literatura y pintura, 1849-1936, Amsterdam: Rodopi, 1998.

-, A la playa. El mar como tema de la modernidad en la pintura española, 1870-1936, Madrid: Fundación Cultural Mapfre Vida, 2000.

MOUNIER, Emmanuel, Introduction aux existentialismes, París: Gallimard, 1973.

MuÑoz, Abelardo, Joaquín Sorolla: viajero de la luz, Valencia: Institució Alfons el Magnánim, 1998

ONís, Federico de, España en América, Madrid: Ediciones de la U de Puerto Rico, 1955.

PANTORBA, Benardino de, Sorolla, estudio biográfico y crítico, Madrid: Compañía Bibliográfica Española, 1963.

PAZ, Octavio, Los hijos del limo: del romanticismo a la vanguardia, Barcelona: SeixBarral, 1974.

PENA, Carmen, «Presentación». AA.VV., Centro y periferia en la modernización de la pintura española (1880-1918), Madrid: Ministerio de Cultura, 1993, 17-25.

PÉREZ ROJAS, Javier, «Un período de esplendor: la pintura valenciana entre 1880 y 1918». AA.VV., Centro y periferia en la modernización de la pintura española (1880-1918), Madrid: Ministerio de Cultura, 1993, 162-73.

RAMA, Ángel, Rubén Darío y el Modernismo (Circunstancia socioeconómica de un arte americano), Caracas: Ediciones de la Biblioteca de la U Central de Venezuela, 1970.

SÁINZ DE MEDRANO, Luis, «Rubén Darío: un periodista ante la modernidad», Revista de Filología Románica 14 (1997): 407-21.

SCHULMAN, Ivan A., «Hacia un discurso crítico del Modernismo concebido como sistema», ¿Qué es el Modernismo? Nueva encuesta. Nuevas lecturas, Ed. Richard A. Cardwell y Bernard McGuirk. Boulder: Society of Spanish and Spanish American Studies, 1993, 257-75.

—, «El Modernismo de Rubén Darío. La otra dimensión», Rubén Darío. La creación, argumento poético y expresivo, Ed. Alberto Acereda, Barcelona: Anthropos, 1997, 40-51.

- y Evelyn P. GARFIELD, 'Las entrañas del vacio': ensayos sobre la modernidad hispanoamericana, México: Cuadernos Americanos, 1984.

STANDISH, Peter, Lírica y color. Desde la pintura a la poesía, Madrid: Iberoamericana, 1999.

Woodbridge, Hensley C., Rubén Darío. A Selected Classified and Annotated Bibliography, Metuchen: Scarecrow Press, 1975.

YURKIÉVICH, Saúl, «Rubén Darío y la modernidad», Plural 9 (1972): 37-41.

-, La movediza modernidad, Madrid: Taurus, 1996.

ZULETA, Ignacio M., La polémica modernista. El Modernismo de mar a mar (1898-1907), Bogotá: Instituto Caro y Cuervo, 1989. 


\title{
RESUMEN
}

Dos visiones del espacio marino como modernidad. Entre la poesía de Rubén Dario y la pintura de Joaquín Sorolla, por Alberto Acereda.

La representación del espacio marino en el fin de siglo hispánico permite establecer algunas consideraciones que favorecen una nueva lectura sobre el difícil concepto de modernidad. El presente artículo estudia dos visiones del espacio marino como modernidad. Por un lado, la pintura del español Joaquín Sorolla percibe el espacio marino como locus amoenus y marco de diversión por el que el arte se convierte en un objeto económico. Por otro lado, el poeta nicaragüense Ruben Darío aspiró a un arte opuesto al materialismo y planteó una visión del mar ligada a una reflexión metafísica de signo existencial. Darío conoció la pintura de Joaquín Sorolla y hasta en algún caso realizó breves comentarios de ella. Esta particularidad nos permite probar de manera más clara las diferencias en sus visiones sobre la modernidad y el arte.

Palabras clave: Rubén Darío. Joaquín Sorolla. Modernidad. Poesía. Pintura. Siglos XIX y $\mathrm{xx}$

\begin{abstract}
The representation of the marine space in Hispanic fin-de-siècle allows us to establish some comments to carry out a new reading of the difficult concept of modernity. The present article studies two visions of the marine space as modernity. On the one hand, the paintings by the Spaniard Joaquín Sorolla present the marine space as a locus amoenus, and as a place for enjoyment where art becomes an economic object. On the other hand, the Nicaraguan poet Rubén Darío intented to create an art opposed to materialism, and he gave us a vision of the ocean linked to a metaphysical meditation of existential tones. Darío was familiar with Joaquín Sorolla's paintings and he even wrote short essays on them. This particular aspect allows us to prove in a clearer way the differences in their visions about modernity and art.
\end{abstract}

Key words: Rubén Darío. Joaquín Sorolla. Modernity. Poetry. Painting. $19^{\text {th }}$ and $20^{\text {th }}$ Centuries. 